\title{
Hanging your software up to dry
}

\author{
By Nancy B. Olson \\ Professor, Memorial Library \\ Mankato State University
}

\section{What to do when the roof leaks on your software collection.}

I arly morning of June 19,1986 , a pipe burs in the ceiling somewhere above the technical services area of Memorial Library, Mankato State University in Mankato, Minnesota. By the time the leak was discovered and a janitorial crew called in, the water was several inches deep in the acquisitions area, and dripping down the stacks of $\mathrm{Na}$ tional Union Catalogs in the cataloging area.

It was not until librarians reported to work that it was discovered water had also come through the ceiling onto trucks of audiovisual materials, including a complete run of the microcomputer software serial, SoftDisk.

The acquisitions area was vacuumed dry.

The wet volumes of the National Union Catalog were sent to be freeze-dried in the usual manner.

The audiovisual items were opened and spread out on shelves and tables for drying. All film and magnetic tape materials were opened and loosened so moisture would not cause layers of film or tape to stick together.

Records were removed from jackets and liners and carefully wiped dry. Study prints were propped against shelves. Posters were laid flat, face up, to dry. Fans were brought from homes to circulate air throughout the area, and all materials dried quite well, though much of the packaging had to be replaced. Many of the paper items were wrinkled or warped, but they were still usable.

The microcomputer software seemed hopeless. The cataloging of this software had been finished the previous day, and the 55 issues of SoftDisk,

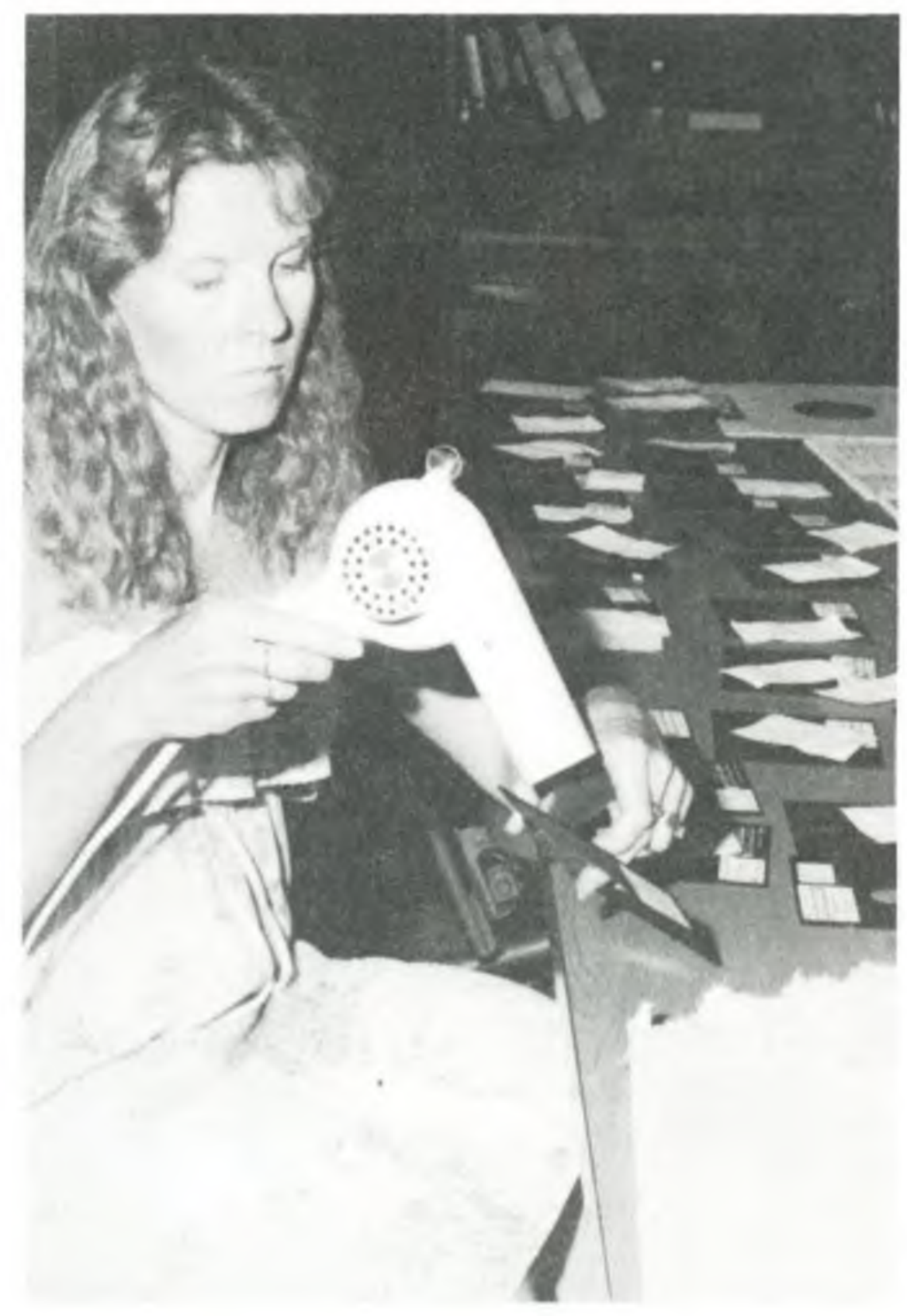

Figure 1. Rosie Nock, library technician, dries a disk with a hair dryer. 


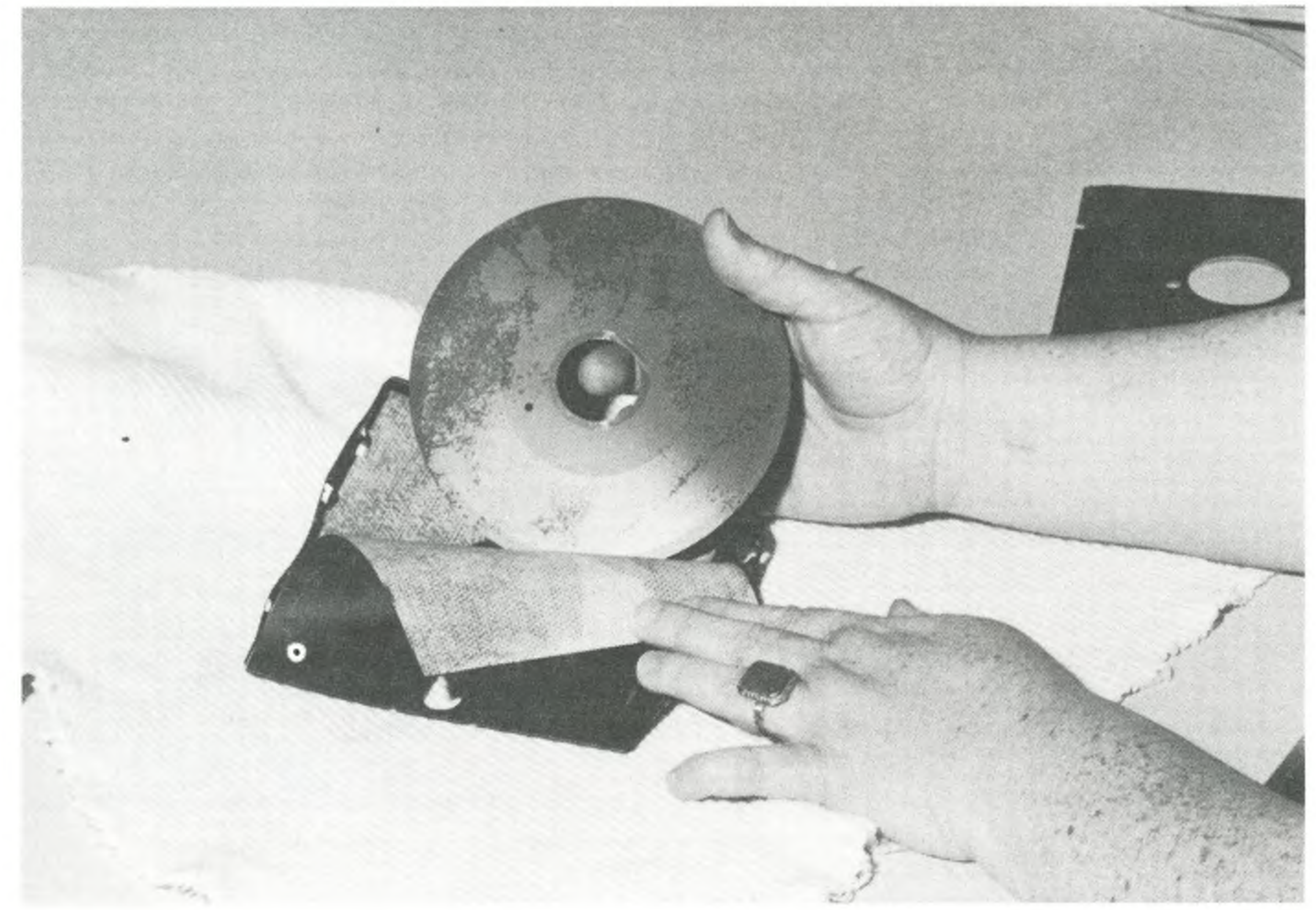

Figure 2. A disk is removed from its plastic sleeve. Note moisture on disk and in lining of sleeve.

most with two disks per issue, were standing almost upright in cardboard boxes, waiting to be labeled with call number and issue number.

Because these disks were loose, in open boxes, water falling onto them from above was directed into the plastic sleeves which enclose the disks themselves. The water could not drain away, as it was held around the disk by the plasticized jacket in which each enclosed disk is slipped when not in use.

Water poured from many of the disks when they were removed from their jackets. It spurted from the plastic sleeve openings when the sleeves were squeezed. It dripped onto the table as we checked disk after disk, hoping to find some that had been spared from the disaster. There were no dry disks.

We assumed these would be a total loss. However, Dr. Edmund Colby, coordinator of our Educational Resource Center, decided to experiment.

Disks are permanently encased in plastic sleeves, with a cloth-type lining that is impregnated with a silicone lubricant. This lining holds moisture. For those disks only slightly wet (no water spurted out when the disk was squeezed) a hair dryer with an "air" setting (no heat) was used to thoroughly dry the sleeve lining (see Figure 1). The disk sleeve was held slightly away from the disk and air was directed into the sleeve, being careful to dry both sides of the disk, both sides of the sleeve lining, and

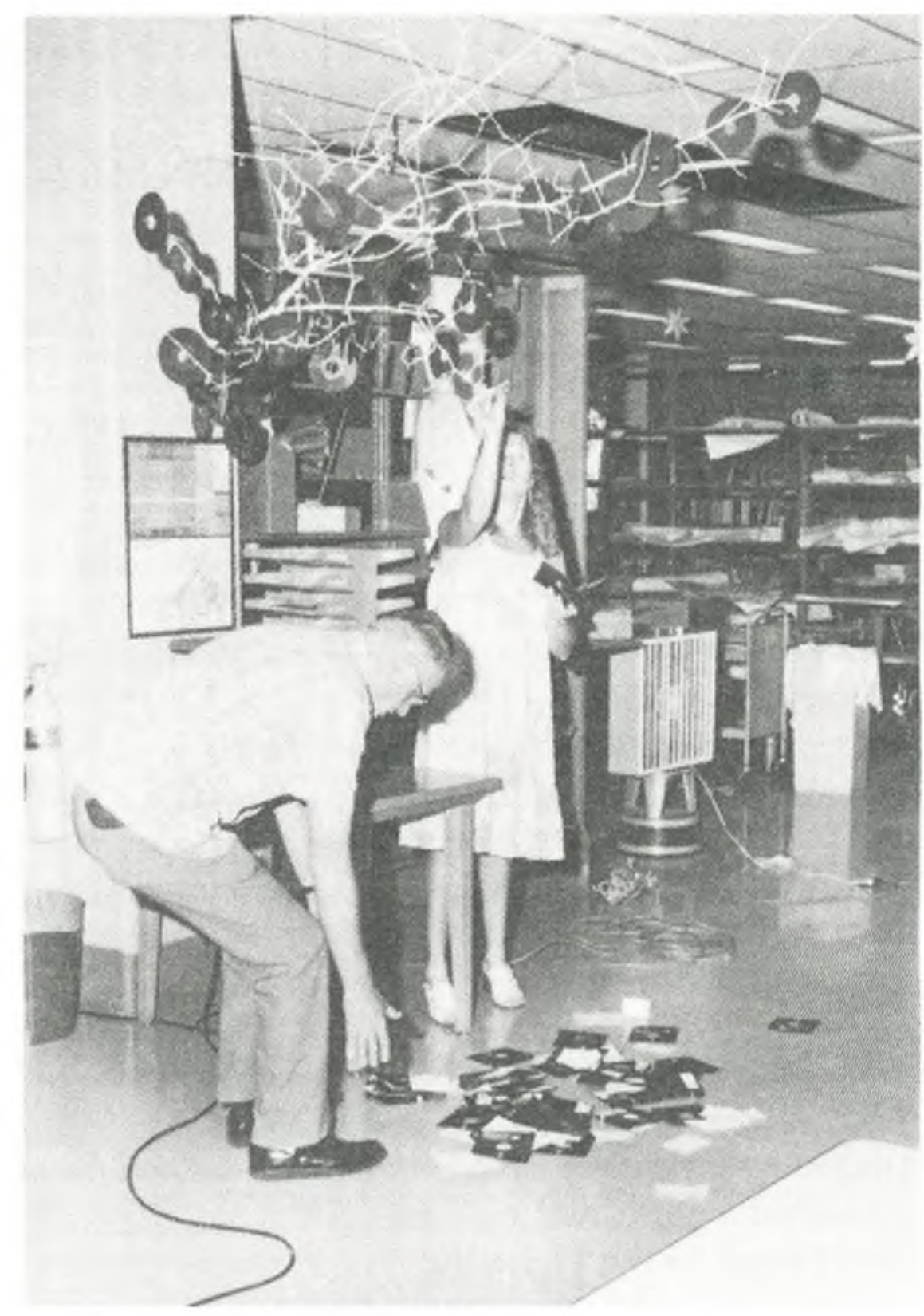

Figure 3. The software tree. 
all corners. These disks were then copied successfully.

The dripping wet disks were peeled out of their plastic sleeves (see Figure 2). The plastic sleeves of some were relatively easy to pop open. Others were more difficult, and a paper cutter was used, first making sure to tap the sleeve to position the disk away from the edge being cut.

Each disk was then wiped dry with a rag! The janitor closet yielded a box of clean, soft, lint-free rags (from old thermal underwear). The waffleweave cloth shown in Figure 2 dried well and did not leave lint on the disks.

The disks were then hung for further air drying on the cataloging department "Easter egg tree" (Figure 3). This procedure kept the disks from touching each other, and also kept the disk surfaces from coming into contact with any other material or contaminants.

A new dry disk was then cut open by trimming off about $1 / 16$ inch of the write-protect edge with a paper cutter. The disk was removed from the plastic cover and set aside for later replacement. One by one the bare disks were slipped into this dry cover, run, and copied. All disks copied successfully, and everything - including the entire microsoftware serial — was salvaged.

\title{
Library consultant in Indonesia
}

\author{
By Tanja Lorkovic \\ Head of Cataloging \\ University of Iowa
}

\section{The state of librarianship in one developing country.}

\section{T} his article was inspired by the consulting report, "The Team Approach to Library Consulting in a Developing Country," by Carolyn A. Snyder, Larry W. Griffin, Andrea Singer, and Roger Beckman of the Indiana University Libraries $(C \& R L$ News, December 1985, pp. 629-32). It prompted me to recount my own experiences as a University of Iowa librarian during a year of consulting internationally at the University of North Sumatra, Medan, Indonesia.

In July 1984 the Office of International Education and Services of the University of Iowa announced that the Midwest Universities Consortium for International Activities (MUCIA) had been awarded a contract funded by the Asian Development Bank (ADB Loan No. 525-INO) for the University of North Sumatra/Universitas Sumatera Utara (USU) Development Project.
The project's objectives were to upgrade academic programs, curriculum, teaching management, library service, and physical facilities of USU. Among the four long-term and 21 short-term consultancies in diverse academic and professional fields was a request for a library specialist. I applied and in September 1984 I was appointed by MUCIA to the position of library specialist for the University of North Sumatra Project. In April 1985 the Project Implementation Unit at USU accepted my appointment. During the negotiation between that Unit and MUCIA, the initial 15 man-months for the library specialist was shortened to 12 manmonths with the provision that the remaining three months would be allocated for a specialized library consultation that might be needed later. The orientation process started at the University of Iowa where I was given a Bahasa Indonesia textbook, 